\title{
Translation of Metaphors in George Orwell's Animal Farm from English to Hindi: A Cognitive Semantic Perspective
}

BABURAM UPADHAYA

\begin{abstract}
Metaphors are prevalent across languages and cultures, but not all metaphors are shared by any two languages. Therefore, it is interesting to see how a work of translation deals with metaphors through a cognitive semantic perspective. This paper investigates how metaphors used by George Orwell in Animal Farm have been translated into Hindi by Sooraj Prakash. The findings show Prakash using culture-specific metaphors in the target text (TT) to provide the metaphorical sense of the target culture and at the same time trying to preserve the metaphors of the source text $(S T)$ wherever they fitted aptly.
\end{abstract}

Keywords: Metaphor, Source Language, Target Language, Culture, Source Text, Target Text.

\section{Metaphor}

Metaphor has traditionally been seen as an embellishment to a language whose purpose is to evoke interest or emotion in the reader or the listener's mind by the use of figurative expressions. These figurative expressions were considered to be the creative work of the writer or the speaker and were generally viewed as serving rhetorical purposes. However, later studies showed that metaphor is not something that belongs to the domain of persuasive speakers or writers but is very much pervasive in everyday life (Lakoff \& Johnson 1980, Johnson 1987, Gibbs \& Steen 1999). Human beings think in terms of metaphors. Our every thought, action, and experience is influenced and motivated by metaphor. In other words, we think, talk, and act in terms of metaphor. The basis of metaphor lies in our conceptual system. This idea was first 
introduced by Lakoff and Johnson in 1980 in their seminal Metaphors We Live By and then later by Gibbs (1990), Kovecses (2002), and other linguists and psycholinguists. They proposed the Conceptual Metaphor Theory, where they emphasize that language is a reflection of the general cognitive system and metaphor is a part of this system. They argue that metaphor provides us structure to what is abstract or less perceptually based experience through our understanding of the spatial, physical, and social world in which we live. Simply put, we understand the abstract in terms of concrete. Since then onwards metaphor has started gaining attention from scholars, as they were interested in finding out how metaphor is involved in different fields of studies. This new approach of metaphor study also found a way in translation studies where translation scholars viewed it as a new perspective on translation strategies.

\section{Translatability of Metaphor}

Viewed from a purely linguistic point, metaphors are not always translatable from one language to another. There are cultural and linguistic barriers that prohibit this act as the target text (TT) may not have the equivalent metaphor of the source text (ST), or it may not have that concept in its culture and language as such. However, Vermeer's (1984, 2014) Skopos theory suggests that it is the function of the TT that determines the translation of the ST. Apart from that, Toury's (1995) target-oriented approach talks about the use of an equivalent expression which is as per the norms of the TT and the target reader. Again, the translation of metaphors depends on the similarity and dissimilarity between the source language (SL) and the target language (TL) with respect to the conceptualisation of certain notions that exist in these respective cultures. So, according to the 'Cognitive Translation Hypothesis' proposed by Mandelblit (1995) when two cultures 
conceptualize experience in a similar way, 'similar mapping conditions,' applies and the task of translation will be easier. Otherwise, 'different mapping conditions' will apply and the task will become more difficult. Therefore, it is important for a translator to be familiar with the conceptual metaphors of both the SL and the TL and the limitations involved in their translation. In this regard, it will be interesting to see in this study how the translator, Suraj Prakash, translates the metaphors used by George Orwell in the English ST to the Hindi TT and what strategies does he adapt to translate these metaphors. Therefore, there has long been a debate going on among translation theorists regarding the translation of metaphors. According to Dagut (1976) and Nida (1964), metaphors are not translatable because of the cultural and linguistic differences between the SL and the TL. Moreover, the creation of a new metaphor for the TT as per the SL may not be a good idea, as this new metaphor may seem alien to the target reader. This alienation to the new metaphor may stem from the unfamiliarity of the conceptual system of the source language and culture and the difference between the conceptualisation of a particular notion in the SL with that of the TL. Therefore, it is important for a translator to be familiar with the conceptual system of both the SL and the TL. This is because the translation of metaphor is not just limited to metaphorical expressions but with the underlying conceptual metaphors of these expressions and also with the conceptual system of both the source and the target culture.

\section{Translation of English Metaphors to Hindi through a Cognitive Semantic Perspective}

As noted earlier, cognitive semantics views metaphor not as an isolated instance of language but very much associated with our everyday thought process. Consequently, in this view, metaphor is "understanding and experiencing one kind of thing 
in terms of another" (Lakoff \& Johnson 1980: 5). To be more specific, we use metaphor to understand the abstract in terms of concrete physical images. And this is not something we do consciously, but often we use them without being aware of it. They are so ingrained in our thought process that many a time they go unnoticed. According to Kövecses (2002: 4), metaphor is "understanding one conceptual domain in terms of another". The former is known as the source domain and the latter the target domain. The source domain is generally concrete in nature whereas the target domain is abstract.

Lakoff and Johnson (1980) have classified conceptual metaphor into three main types: structural, ontological and orientational. Structural metaphors systematically structure one concept in terms of another. For instance, in the conceptual metaphor TIME IS MONEY, the concept of time is partially structured, understood, and talked about in terms of money (Lakoff \& Johnson 1980). This conventional conceptual metaphor is realized in metaphorical expressions, such as 'I don't have time', 'Please don't waste my time', and 'She spends her time in useless activities'.

Orientational metaphors, on the other hand, are metaphors that provide a spatial orientation, such as up-down, front-back to a concept. For instance, the conceptual metaphor HAPPY IS UP is realized in metaphorical expressions, such as 'She is in high spirits' and 'That lifted my spirits'. Similarly, the conceptual metaphor SAD IS DOWN is realized in metaphorical expressions, such as 'I feel low' and 'That dropped his spirits'. These conceptual metaphors have a physical basis. When we are happy, we tend to be in an erect posture; and when we feel sad, we tend to be in a drooping posture.

Ontological Metaphors, lastly, are metaphors that make us view aspects of our experience in terms of some entities or 
Translation of Metaphors in George Orwell's Animal Farm...

substances. Personification is one such example, which enables us to understand physical objects in terms of human attributes.

In the next section, I will deal with how the metaphors used in the novella Animal Farm by Orwell have been translated into the Hindi translation by Sooraj Prakash through a cognitive semantic perspective. Due to the small-scale nature of this paper, I am dealing only with the translation of metaphors in the first chapter. First, I will list the English metaphorical expressions along with their respective conceptual metaphors. Then I will list the Hindi translations of the expressions along with their respective conceptual metaphors. Finally, I will examine how these expressions have been translated into Hindi.

\begin{tabular}{|l|l|}
\hline English Metaphorical Expression & Conceptual Metaphor \\
\hline i. Spent their Sundays & $\begin{array}{l}\text { LEISURE TIME IS A LIMITED } \\
\text { RESOURCE }\end{array}$ \\
\hline ii. Pass on to you such wisdom & MOVEMENT IS ON \\
\hline iii. I have had a long life & LIFE IS A JOURNEY \\
\hline iv. Let us face it (life) & $\begin{array}{l}\text { LIFE IS A PHYSICAL BEING OR } \\
\text { OBJECT WHICH HAS A FRONT } \\
\text { AND A BACK }\end{array}$ \\
\hline v. Last atom of our strength & $\begin{array}{l}\text { STRENGTH IS A CHEMICAL } \\
\text { ELEMENT }\end{array}$ \\
\hline vi. Dogs have no better fate & $\begin{array}{l}\text { FATE IS SOMETHING THAT CAN } \\
\text { BE POSSESSED }\end{array}$ \\
\hline $\begin{array}{l}\text { vii. Adopt his vices } \\
\text { viii. } \quad \text {-.who (pigs) settled down in } \\
\text { the straw }\end{array}$ & $\begin{array}{l}\text { RESTING HAS DOWNWARD } \\
\text { ORIENTATION }\end{array}$ \\
\hline $\begin{array}{l}\text { ix. The two horses had just lain } \\
\text { down }\end{array}$ & $\begin{array}{l}\text { RESTING HAS DOWNWARD } \\
\text { ORIENTATION }\end{array}$ \\
\hline $\begin{array}{l}\text { x. The ducklings nestled down } \\
\text { inside it }\end{array}$ & $\begin{array}{l}\text { RESTING HAS DOWNWARD } \\
\text { ORIENTATION }\end{array}$ \\
\hline $\begin{array}{l}\text { xi. Even the stupidest of them } \\
\text { had already picked up the tune }\end{array}$ & $\begin{array}{l}\text { AQUISITION OF TUNE HAS } \\
\text { UPWARD ORIENTATION }\end{array}$ \\
\hline $\begin{array}{l}\text { xii. The meeting broke up } \\
\text { hurriedly }\end{array}$ & COMPLETION IS UP \\
\hline $\begin{array}{l}\text { xiii. Words had gone round } \\
\text { during the day }\end{array}$ & $\begin{array}{l}\text { WORDS ARE PHYSICAL BEINGS } \\
\text { CAPABLE OF MOVEMENT }\end{array}$ \\
\hline $\begin{array}{l}\text { xiv. Is it because this land of } \\
\text { ours England) is so poor that it }\end{array}$ & $\begin{array}{l}\text { NATION IS A NURTURANT } \\
\text { PARENT }\end{array}$ \\
\hline
\end{tabular}


Baburam Upadhaya

\begin{tabular}{|l|ll|}
\hline $\begin{array}{l}\text { cannot afford a decent life to those } \\
\text { who dwell upon it? }\end{array}$ & & \\
\hline $\begin{array}{l}\text { xv. …it (England) is capable of } \\
\text { affording food in abundance... }\end{array}$ & $\begin{array}{l}\text { NATION IS A } \\
\text { PARENT }\end{array}$ & NURTURANT \\
\hline $\begin{array}{l}\text { xvi. No argument must lead you } \\
\text { astray }\end{array}$ & ARGUMENT IS AN EVIL BEING \\
\hline
\end{tabular}

\begin{tabular}{|c|c|c|}
\hline & Translated Hindi Expression & Conceptual Metaphor \\
\hline$i$. & $\begin{array}{l}\text { Ravibar ki chhuttiya...gujarte } \\
\text { the }\end{array}$ & LEISURE TIME IS A JOURNEY \\
\hline ii. & Use (buddhimata ko) ...deta hu & --- \\
\hline iii. & Bharpur jivan ko ji liya & LIFE IS A CONTAINER \\
\hline$i v$. & $\begin{array}{l}\begin{array}{l}\text { Isme (zindgime) jhank kar } \\
\text { dekhen }\end{array} \\
\end{array}$ & LIFE IS A CONTAINER/OBJECT \\
\hline$v$. & $\begin{array}{l}\text { Khun ki aakhiri boond tak } \\
\text { kaam karne ko majbur kiya jata } \\
\text { hai }\end{array}$ & STRENGTH IS BLOOD \\
\hline$v i$. & $\begin{array}{l}\text { Kutto ki zindgi me bhi isse } \\
\text { behtar kuch nai likha hua hai }\end{array}$ & LIFE IS A WRITTEN PAPER \\
\hline vii. & Uski buraiyon ko mat apnana & VICES ARE PHYSICAL BEINGS \\
\hline & $\begin{array}{l}\ldots \text { (suwar) puwal par pasar } \\
\text { gaye }\end{array}$ & --- \\
\hline$i x$. & Dono ghode abhi baithe hi the & $\overline{---}$ \\
\hline$x$. & $\begin{array}{l}\text { Battakh ke bacche iske bhitar } \\
\text { dubak kar baith gaye }\end{array}$ & -- \\
\hline$x i$. & $\begin{array}{l}\text { Sabse bhondu pashuon ki juban } \\
\text { par bhi iski dhun chad gayi }\end{array}$ & $\begin{array}{l}\text { AQUISITION OF TUNE } \text { HAS } \\
\text { UPWARD DIRECTION }\end{array}$ \\
\hline xii. & $\begin{array}{l}\text { Baithak aphra-taphri me } \\
\text { khatam ho gayi }\end{array}$ & --- \\
\hline xiii. & $\begin{array}{l}\text { Din me hi charo taraf yeh } \\
\text { khabar phail chuki thi }\end{array}$ & NEWS IS FIRE/FLUID \\
\hline xiv. & $\begin{array}{l}\text { Kya...humari dharti itni garib } \\
\text { hai ki ye is (England) par } \\
\text { rehnewalon ko ek shandar } \\
\text { zindgi muhaiya nahi kara } \\
\text { sakti? }\end{array}$ & $\begin{array}{llll}\text { NATION } & \text { IS } & \text { A } & \text { NURTURANT } \\
\text { PARENT } & & & \end{array}$ \\
\hline$x v$. & $\begin{array}{l}\text { Isme (England) itni kshamta } \\
\text { hai ki ab...usse kai guna adhik } \\
\text { pashuon ka khub acchi tarah se } \\
\text { bharan-poshan kar sakti hai }\end{array}$ & $\begin{array}{llll}\text { NATION } & \text { IS } & \text { A } & \text { NURTURANT } \\
\text { PARENT } & & & \end{array}$ \\
\hline$x v i$. & $\begin{array}{l}\text { Koi bhi tark-kutark tumhe } \\
\text { bahkaye-bhatkaye nahi }\end{array}$ & ARGUMENT IS AN EVIL BEING \\
\hline
\end{tabular}




\section{Analysis and Discussion of the Strategies used in the Hindi Translation}

After identifying the metaphorical expressions in the ST and their respective conceptual metaphors, I have found more dissimilarity than similarity in how the same thing is being conceptually structured in the TT. For example, in example (i), Sundays are conceptualised as limited resources in the ST, whereas in the TT, they are conceptualised as a journey undertaken. Furthermore, the translator elaborates this concept by using the expression chhuttiyan, which means 'holidays', to avoid ambiguity and to make it more culturally appropriate for the TT as Sundays are not generally viewed as leisure time in the target culture. This is in accordance with the functionoriented approach by Reiss (1989), Reiss and Vermeer (1984), and Nord (1997) who view translation as a communicative process intended to serve a particular purpose in the target language. This includes the coherence rule of Vermeer's Skopos theory (Reiss \& Vermeer 1984) which holds that TT should convey the idea of the ST in such a manner that it is apprehensible to its target reader by taking into consideration the knowledge and the setting of the reader.

In example (ii), we see that in the ST, movement is described by the orientational metaphor MOVEMENT IS ON. In the TT, movement is described in a conventional literal sense. But given the context, the expression deta $h u$ aptly fits in here. Although the meaning of 'pass on' and dena (to give) sounds similar, the former indicates a continuous movement along a path, whereas the latter indicates movement from one point to another. This is because English is a satellite-framed language and its speakers tend to provide richer descriptions of path trajectories as compared to the speakers of a verb-framed language (here Hindi) (Cadierno 2008; Slobin 1997). That is 
why by using the expression deta $h u$ the translator kept the coherence of the TT organic and made it sound natural.

The ST metaphorical expression in example (iii) conceptualizes life as a journey. When Old Major says, 'I have had a long life', he sees life as a journey, which could be either a short one or a long one. However, in the Hindi translation, life is described as a container because the phrase bharpur jiwan ko ji liya means the Old Major had lived a life to his heart's content. This is in fact true when we look at the next sentence where Old Major says 'I have had much time for thought as I lay alone in my stall, and I think I may say that I understand the nature of life on this earth as well as any animal now living' (9). So, compared to other animals on the farm, the Old Major indeed lived a meaningful and fulfilled life. Therefore, bharpur jiwan ko ji liya is the better Hindi translation for the phrase 'have had a long life' than would have been the direct translation mene lambi zindgi ji li hai derived from the conceptual metaphor LIFE IS A JOURNEY. Here, the idea is conceptualized differently in order to avoid ambiguity and to make it explicit for the target readers. This is a case of a good translation.

The metaphorical expression 'let us face it (life)' in example (iv) conceptualizes life as a physical object or being with a front and a back. Here, only the body part 'face' is used for the whole being and not the other body parts because it is only the face that gives us the identity of a person and not their other body parts. So, in order to recognise a person, we need to see his face. On the other hand, the Hindi translation isme (zindgime) jhank kar dekhen is derived from the conceptual metaphor LIFE IS A CONTAINER/OBJECT. The reason behind using this conceptual metaphor could be because, in the target culture, life is something that is looked upon inwardly; the belief in the spirit within oneself. But in the source culture, 
life is something that has an outward existence, and that's why the expression 'let us face it' is used. So, the translator beautifully captures the conceptual system of the target reader in the TT.

In example (v), the expression 'last atom of our strength', is derived from the conceptual metaphor STRENGTH IS A CHEMICAL ELEMENT. But the Hindi translation is khoon ki aakhiri boond tak kaam karne ko majbur kiya jata hai is derived from the conceptual metaphor STRENGTH IS BLOOD. In the target culture, blood is generally associated with strength. This can be seen in other expressions like khoon ko pasina banana and humare khoon me dum hai. Keeping this aspect in mind, the translator used this metaphor to express strength. Moreover, the conceptual metaphor STRENGTH IS A CHEMICAL ELEMENT in the TT is somewhat alien to the target reader. So, instead of using the same conceptual metaphor, the translator used the one which is familiar to the target reader.

In example (vi), the metaphorical expression 'dogs have no better fate' has been derived from the conceptual metaphor FATE IS SOMETHING THAT CAN BE POSSESSED. A similar metaphorical expression could also have been derived from the same conceptual metaphor in the Hindi translation. But the translator thought of being more explicit and instead chose the conceptual metaphor LIFE IS A WRITTEN PAPER from which the metaphorical expression kutto ki zindgi me bhi isse behtar kuch nai likha hua hai has been derived. This is because of the belief in the target culture that the deity Shasti (literally, the sixth one) writes the destiny of an infant on the sixth day of their birth.

However, the metaphorical expressions in example (vii) 'adopt his vices' in the ST and uski buraiyon ko mat apnana in the TT 
have been derived from the same conceptual metaphor VICES ARE PHYSICAL BEINGS.

In the examples (viii), (ix), and (x), we see that the metaphorical expressions have been derived from the orientational metaphor RESTING HAS DOWNWARD ORIENTATION in the ST. This is because when we rest, we generally hang downwards limply. But in the Hindi translations, the translator uses the literal meaning of these metaphorical expressions. One reason for this could be again English being a satellite-framed language, which tends to provide richer descriptions of path trajectories than Hindi, which is a verb-framed language (Cadierno 2008; Slobin 1997). That is why, to keep the coherence of the TT organic and to sound natural, the translator used the literal meaning instead of using any metaphorical expressions. This may be also because the translator could not find any appropriate metaphorical expressions in the Hindi translations.

In example (xi), the metaphorical expression in the ST 'even the stupidest of them had already picked up the tune', and the metaphorical expression in the TT sabse bhondu pashuon $k i$ juban par bhi iski dhun chad gayi have been derived from the same orientational metaphor ACQUISITION OF TUNE HAS AN UPWARD ORIENTATION.

In example (xii), the orientational metaphor COMPLETION IS UP is used to describe the completion of an event (here meeting), whereas in the Hindi translation, the conventional literal word khatam is used.

The metaphorical expression 'words had gone round during the day' used in the example (xiii) in the ST is derived from the metaphor WORDS ARE PHYSICAL BEINGS CAPABLE OF MOVEMENT. But, the Hindi translation din me hi charo taraf yeh khabar phail chuki thi is derived from a different conceptual metaphor NEWS IS FIRE/FLUID. In this case, 
also, the translator tried to stick to the basic conceptual system of the target reader and avoided ambiguity.

In the next two examples (xiv) \& (xv), in both the ST and the TT, the metaphorical expressions are derived from the same conceptual metaphor, which conceptualizes the nation as a nurturant parent. The translator again sticks to the basic conceptual system of the target reader where they refer to the land they live on as dharti mata (Mother Earth).

We see the similar thing happening again in example (xvi), where argument is seen as an evil being in both the ST and in the TT. But in the TT, the translator used an extra word kutark with tark to avoid any kind of ambiguity. The ambiguity might have arisen in the mind of the target reader that how could any tark mislead (bahka-bhatka) an individual because tark is often thought as something that gives one a clear perception about something. So, by the use of that extra word kutark, he cleared the doubt that might have arisen in the target reader's mind.

After identifying and investigating the metaphorical expressions and how they are derived from different conceptual metaphors, I would like to do an analysis of the strategy the translator used in translating the conceptual metaphors from the ST to the TT. Before this, I would like to identify the translation patterns:

(a) Same conceptual metaphor and equivalent metaphorical expressions.

For example, the expression 'adopt his vices' in the ST and its equivalent expression uski buraiyon ko mat apnana in the TT are derived from the same conceptual metaphor VICES ARE PHYSICAL BEINGS.

Also, the expressions '...it (England) is capable of affording food in abundance...' in the ST and Isme (England) itni 
Baburam Upadhaya

kshamta hai ki ab...usse kai guna adhik pashuon ka khub acchi tarah se bharan-poshan kar sakti hai in the TT are equivalent to each other and are derived from the same conceptual metaphor NATION IS A NURTURANT PARENT.

(b) Similar conceptual metaphor but different metaphorical expressions.

For example, the expressions 'Even the stupidest of them had already picked up the tune' in the ST and sabse bhondu pashuon ki juban par bhi iski dhun chad gayi in the TT are derived from the conceptual metaphor ACQUISITION OF TUNE HAS UPWARD ORIENTATION.

(c) Different conceptual metaphors

For example, the expression 'spent their Sundays' is derived from the conceptual metaphor LEISURE TIME IS A LIMITED RESOURCE in the ST, whereas the expression ravibar ki chhuttiya... gujarte the in the TT is derived from the metaphor LEISURE TIME IS A JOURNEY.

(d) Conceptual metaphor vs literal meaning

For example, the expressions 'settle down', 'nestle down' and 'lain down' is derived from the conceptual metaphor RESTING HAS DOWNWARD ORIENTATION in the ST, whereas these expressions have been translated literally in the TT.

From the above investigation about the translation of metaphors from the ST to TT, one thing becomes clear that the study of metaphor translation is inseparable from the conceptual system as the conceptual metaphors and their metaphorical expressions may not be the same in the source and the target culture. This dissimilarity of conceptual metaphors across different cultures and languages poses problems for the translation of metaphors from one language to 
another (Deignan, Gabrys, \& Solska 1997: 352). Here, it is seen that the conceptual metaphors used in the source text may be either similar or dissimilar to the target text. The dissimilarities should not be taken as mistranslations, but rather a different way of expressing the same metaphor in the TT. This is because the target language may sometimes not have a conceptually and linguistically corresponding metaphor or sometimes the translator decides to use another conceptual metaphor in the TT. This is done to avoid word-for-word translation of metaphorical expressions especially in TLs, which do not share the same conceptual metaphor with that of the SL. In such cases, word-for-word translation generally does not yield intended results.

The present paper establishes the fact that conceptual metaphor should be taken into account in translation studies. This is because it has significant cognitive and pragmatic functions which when explored and utilised properly by the translator can bring about a great difference to his work. From the investigation, it is also seen that conceptual metaphors are indeed pervasive in nature, which is in line with Lakoff and Johnson's theory of conceptual metaphor (1980). Our investigation shows that it is pervasive in both the source and the target language and they have their own sets of conceptual metaphors, some of which are similar and some not.

Now, the strategy, the translator, Suraj Prakash, adopted in translating the metaphors from the ST to Hindi is that of explication, elaboration, and using different TT metaphorical expressions. The specific meaning of the ST metaphor has been broadened through different and adaptive TT metaphors that convey the similar metaphorical sense of the ST metaphor. The ST metaphors have been elaborated to avoid any ambiguity in the target reader so that it forms a cohesive and readable TT sentence. The culture-specific metaphors have 
been used in the TT to provide the metaphorical sense of the target culture. Some of the conceptual metaphors of the ST have been preserved in the TT too. This is because these metaphors are conceptualised similarly in both the SL and the TL which, in turn, suggests the translatability of metaphors across varied cultures. It invalidates the claim made by Dagut (1976) and Nida (1964) that metaphors are untranslatable across cultures. On the whole, I found that the translation strategies, adopted by Prakash, for transferring the metaphors from the ST to the TT to be orientated towards target readership. This is observed in his use of acceptable, normal, and familiar means of communication that the target reader is used to in his culture.

Moreover, we also saw how similarities in the conceptualizations between the target culture and the source culture facilitate the translation of metaphors from the ST to the TT and how differences in the conceptualizations can hamper a smooth transference of metaphors to the TT. This is in line with the Mandelblit (1995) assumption of 'similar mapping conditions' and 'different mapping conditions' in the translatability of metaphors across languages.

\section{Conclusion}

From the above discussion, it has been observed that linguistic differences may seem to be creating hurdles in translating metaphors from the ST to the TT. However, if looked at from the cognitive semantic perspective, linguistic differences can be handled successfully if the translator is familiar with the conceptual system of both the SL and the TL. In this study, I think the translator, Sooraj Prakash, could successfully convey the metaphorical sense to the target readership through readable and cohesive TT sentences, by generating parallel and familiar conceptual metaphors in the TT, through explanatory information, and by using familiar and conventional metaphors 
Translation of Metaphors in George Orwell's Animal Farm...

in TT instead of the unfamiliar and culture-specific ST metaphors.

\section{References}

CAdierno, TeresA. 2008. Learning to Talk about Motion in a Foreign Language. In Nick Ellis \& Peter Robinson (eds.), Handbook of Cognitive Linguistics and Second Language Acquisition. 239-275. New York: Routledge.

Dagut, Menachem. 1976. Can Metaphor be Translated? Babel 12 (1). 21-33.

Deignan, Alice, Gabrys, Danuta, \& Solska, AgnieszKa. 1997. Teaching English Metaphors Using CrossLinguistic Awareness-Raising Activities. ELT Journal 51 (4). 352-60.

GiBBS, Roland. W. 1990. Psycholinguistic Studies on the Conceptual Basis of Idiomaticity. Cognitive Linguistics 1 (4). 417-451.

GibBs, Raymond. W. \& Steen, Gerard. J. (eds.). 1999. Metaphor in Cognitive Linguistics. Amsterdam: John Benjamins.

JOHnSOn, MARK. 1987. The Body in the Mind: The Bodily Basis of Meaning, Imagination, and Reason. Chicago: Chicago University Press.

Kövecses, Zoltán. 2002. Metaphor: A Practical Introduction. New York: Oxford University Press.

LAKOFF, GEORGE \& JOHnSON, MARK. 1980. Metaphors We Live by. London: The University of Chicago Press.

Mandelblit, NiLi. 1995. The Cognitive View of Metaphor and its Implication for Translation Theory. In Marcel Thelen and Barbara Lewandowska-Tomaszczyk (eds.), Translation and Meaning: Part 3. 482- 495. Maastricht: Maastricht University Press. 
Baburam Upadhaya

NidA, EugenE. A. 1964. Toward a Science of Translating: With Special Reference to Principles and Procedures Involved in Bible Translating. Brill Archive.

NORD, Christiane. 1997. Translating as a Purposeful Activity: Functional Approaches Explained. Manchester: St. Jerome.

ORWELL, GEORGE. 1945. Animal Farm. http://www.limpidsoft.com/small/animalfarm.pdf

Orwell, GeOrge. 1945. Animal Farm. (Sooraj Prakash, Trans.).

https://ia803106.us.archive.org/18/items/AnimalFarm-

Hindi/AnimalFarm-Hindi.pdf

Reiss, KatharinA. 1989. Text Types, Translation Types and Translation Assessment. (Andrew Chesterman, Trans.). In Andrew Chesterman (ed.), Readings in Translation Theory. 105- 115. Helsinki: Oy Finn Lectura Ab.

Reiss, KATHARINA \& VERMEeR, HANS. J. 2014. Towards a General Theory of Translational Action: Skopos Theory Explained. (C, Nord, Trans.). Hoboken: Taylor and Francis. Toury, GIDEON. 1995. Descriptive Translation Studies and Beyond. Amsterdam/Philadelphia: John Benjamins Pub.

$* * *$

\section{Cite This Work:}

UpADHAYA, BABURAM. 2021. Translation of Metaphors in George Orwell's Animal Farm from English to Hindi: A Cognitive Semantic Perspective. Translation Today, Vol. 15(1). 191-206. DOI:10.46623/tt/2021.15.1.no3 